\title{
Marital Conflict and Job Burnout
}

\section{Hajihasani $\mathbf{M}^{*}$}

Faculty Member, Literature and Human Sciences, Shahrekord University, Iran

*Corresponding author: Mehrdad Hajihasani, Faculty Member, Literature and Human Sciences, Shahrekord University, Iran, Tel: 09128484663; Email: mehrdadhajhasani@gmail.com

\section{Research article \\ Volume 1 Issue 3}

Received Date: November 09, 2017

Published Date: November 21, 2017

DOI: $10.23880 /$ eoij-16000123

\section{Abstract}

The current research aimed at investigating the relationship between marital conflict and job burnout.In this research a total sample of 245 teachers were chosen by cluster sampling. The sampled teachers were asked to fill out theMarital ConflictQuestionnaire and Job Burnout Questionnaire.Pearson correlation coefficient showed a significant relationship between marital conflict and job burnout. The potential reasons for and implications of this finding were discussed in this article.

Keywords: Marital conflict; Self-differentiation; Occupational stress; Job burnout

\section{Introduction}

One of the major occupational problems usually seen as a reaction to job and organizational pressures among human services employees is the job burnout phenomenon. Job burnout is the reduction of individual's ability to adapt to stressors. It is a syndrome consisting of physical and emotional fatigue leading to a negative self-concept in the individual, negative attitude toward the job and the lack of communication with clientele while performing duty [1]. The term "job burnout" was first proposed by Freuden berger [2]. He investigated job burnout phenomenon in social workers. Westman, Etision and Danon [3] considered job burnout as a psychological stress induced by chronic daily stress. Maslach and Jackson [4] believe that job burnout does not occur suddenly, but it is the result of working in a long period of time. They believe that job burnout has three main components as follows: Emotional exhaustion: it is a state in which the individual has lost his emotional forces and is incapable of establishing emotional relationship with others. Depersonalization: in depersonalization state, individuals who have experienced emotional exhaustion in the first stage do not have adequate energy to take care of their job and work environment, therefore, the individual is willing to protect himself / herself. To attain such a goal, he/ she may disconnect his/ her relationship with other employees. Additionally, in this dimension of job burnout, the individual may show negative, faulty or indifferent attitudes and behaviors to others namely colleagues or customers. Individual inefficiency: in this dimension of job burnout, people begin to negatively judge their abilities and they feel they have not enough competencies expected in their job.

Also, in educational organizations like other organizations, each new member in its first professional contact hope to be faced an appropriate environment to be able to meet his/her psychological, social, and economic needs in a desirable way. School teachers are one of the sectors of society whose mental health is worth thinking about. Due to intense work and problems they experienced in their interpersonal relationships at school with school manager and other colleagues, as well as the extra energy they spent to control abnormal behaviors of students, teachers are constantly in a state of tension and stress. Therefore, it is more likely that they are exposed to job burnout. As education system is of paramount importance in every country, and the quality of this educational system depends on the teachers' efficiency, it is undoubtedly necessary to address factors such as job burnout which affect teachers' efficiency. 


\section{Ergonomics International Journal}

Several studies have been conducted regarding teachers job burnout. In some of these research studies variables such as gender, age, teaching history, marital status, and the type of student that the teacher works with are regarded as variables affecting job burnout $[5,6]$. As job burnout has several causes, in the current research, the relationship between marital conflict and job burnout is investigated. The occurrence of marital conflict in humans' relationships with each other is common and inevitable, and the conflict can be called as the most common phenomenon existing in humans' relationships. Conflict occurs when an individual's actions interfere with the actions of another person. As long as two persons get closer to each other, the potential of conflict increases [7]. The man and woman who join each other have a unique and separate psychological heritage which is entered into their marital relationship. Each of them has a personal history and unique personality and introduces them into all relations with his/her spouse. As the man and woman still react to their past introjections, they cannot behave based on the current reality, thus, couples conflict is inevitable [8].

In several research studies, the role of marital conflict in the occurrence of problems such as job burnout in different occupational groups has been directly and indirectly investigated. Rice [9] believes that marital problems and family stress are the serious cause of emotional and behavioral problems amongst doctors. In the research study conducted by Maghsoudi and Mohamadi [10] with the aim to investigate the relationship between job burnout and marital burnout in obstetrician female doctors in hospitals of Tehran city, it was concluded that job burnout can be predicted based on marital burnout components.

\section{Methodology}

The current research population is composed of all female elementary school teachers of Tehran city in 2011.Samplewas selected using random cluster sampling method. From 19 education regions of Tehran city, 5 regions including regions $1,2,3,6$, and 8 were selected randomly. Then 400 teachers were selected amongst these regions randomly and were studied using 5 questionnaires of marital conflict and job burnout. Of nearly 400 questionnaires that were sent out, only245werecompleted and returned and could be used, therefore, this research includes 245 female teachers in Tehran city.

\section{Marital Conflict Inventory}

This questionnaire is a test with 42 questions prepared for measuring marital conflicts and using in Iranian society. It measures 7 aspects of marital conflicts including decreased cooperation, decreased sexual intercourse, increased children's protection, increased personal relations with his/her own kin, decreased family relations with the spouse's kin, and separating financial affairs from each other. Cranbach's alpha coefficient for the entire of the questionnaire is 0.71 and it ranges from 0.60 to 0.81 for its 7 scales. The questionnaire is scored using 5-point Likert scale [11].

\section{Geldard Occupational Burnout Inventory}

This questionnaire was prepared first to measure counselors' burnout and currently it is used to measure job burnout. This tool has 40 statements showing the individual's feeling toward his/her job, and that to what extent the individuals at risk of job burnout are. According to the norm of occupational burnout questionnaire by Geldard, individuals are classified into4categories including: 1) individuals who are very active (job burnout score below 81), 2) individuals who perform their job well (job burnout score ranges from 81 to 120), 3) individuals who do not have a good status (job burnout score ranges from121 to 200), and 4) individuals who need an immediate action (job burnout score higher than 200). Khakpour and Birashk calculated Cranbach's alpha coefficient of job burnout test to be 0.86, and Esfandiari reported it to be 0.73 using test-retest methods [12].

\begin{tabular}{|c|c|c|c|}
\hline Variable name & $\mathbf{N}$ & Mean & Standard deviation \\
\hline Marital conflict & 245 & $112 / 67$ & $33 / 55$ \\
\hline Job burnout & 245 & $141 / 08$ & $23 / 76$ \\
\hline
\end{tabular}

Table 1: Frequency of research variables.

As shown in Table 1, the mean and standard deviation for marital conflict are 112.67 and 33.52, respectively, and for job burnout are 141.08 and 23.76, respectively.

\begin{tabular}{|c|c|c|}
\hline Variable & Marital conflict & Job burnout \\
\hline Marital conflict & 1 & \\
\hline Job burnout & $* 0 / 58$ & 1 \\
\hline
\end{tabular}

*correlation is significant at the 0.01 level.

Table 2: Results of Pearson correlation between variables.

As shown in table 2, the correlation between marital conflict and job burnout variables is 0.58 . It is significant at the 0.01 level.

\section{Discussion and Conclusion}

The main aim of the current research is to investigate the relationship between marital conflict and job burnout of female teachers in Tehran city. Results of Pearson correlation show that marital conflict positively predicts job burnout. No research study was found that 


\section{Ergonomics International Journal}

directly investigated the relationship between marital conflict and job burnout. But findings are partly in agreement with those obtained by Rice, Maghsoudi $[9,10]$. To explain these findings it can be said that according to Olsen [13] couples who have high marital conflict show higher levels of inability in their interactions in comparison to those who will not experience any conflict in the future.

Couples who do not have correct interactive patterns before marriage especially those who enter into a relationship with inability, withdrawal and negative emotions, are at the higher risk of marital disputes and divorce. Therefore, considering these components, it can be said that due to interpersonal problems, individuals with marital conflict are more likely to lose their interest in their job, and they sometimes quit it. These can cause persons to be more prone to suffer from job burnout. In Shafieinia's view [14], the relationship between couples who are easily challenged affects the smallest daily activities of the individual and put various aspects of life to trouble. Blumstein and Schwartz [13] believe that couples who experience more conflicts over money, women employment, power, or sexual relationships are more likely to get divorced. Therefore this factor acts as a faulty cycle and adversely affects occupational activities. Mahoney [15] believes that if marital conflict is weakly managed, it will ruin marital life and will negatively affect physical and emotional health.

As in addition to their job role, female teachers play the role of wives and mothers, it can be said that they may not be able to perform their duties well at certain times. This role interference raises marital conflict rate, and because marital conflict results in outcomes such as stress, anxiety, tension, absence from work, delayed arrival at work or early departure from work, individuals with higher marital conflict can be expected to be more prone to suffer from job burnout.

Perhaps, it can be said that individuals with high marital conflict spent most of their time and energy to resolve this conflict, and when they face pressures of work they are incapable of making the right decision due to their marital conflict and gradually lose their interest in their job. They may lose their colleagues' supports in their work place over time due to their maladaptive behaviors caused by the pressure of personal conflict. Decreased cooperation of colleagues in a workplace can reduce employee motivation in the workplace and may increase conflicts. Therefore, in the light of the above it can be expected that individuals who deal with higher marital conflict are expected to be more prone to suffer from job burnout.

\section{Research Limitation}

As the current sample consisted of female elementary school teachers we should be cautious about generalizing the results to teachers teaching at other levels, as well as to male teachers.

\section{Research Recommendations}

As the results obtained by the current research yield a significant relationship between job burnout and marital conflict, education system officials are recommended to consider these factors in their macroplanning to deal with job burnout syndrome.

\section{References}

1. Pardakhtchi M, Ahmadi G, Arezeomandi F (2011) Relationship between work life quality and job burnout in teachers. Quietly Journal of Educational Leadership \& Administration 3(3): 5-25.

2. Tanhan F, Cam Z (2011) The relation between mobbing behaviors teachers in elementary schools are exposed to and their burnout levels. Procedia Social and Behavioral Sciences 15: 2704-2709.

3. Westman M, Etsion D, Danon E (2001) Job insecurity and crossover of burnout in married couples. Journal of organization behavior 22(5): 467-481.

4. Iacovides A, Fountoulakis KN, Kaprinis S, Kaprinis G (2003) The relationship between job stress, burnout and clinical depression. Journal of Affective Disorders 75(3): 209-221.

5. Rudow B (1999) Stress and burnout in the teaching profession: European studies, issues, and research perspectives. Cambridge University Press, New York.

6. Sas C, Boros D, Bonchis E (2011) Aspects of the burnout syndrome within the teaching staff. Procedia Social and Behavioral Sciences 11: 266270.

7. Moradi A, Shanaei B (2005) Effectiveness of training problem-solving on parent-child conflicts in students. Journal of counseling research 20-5.

8. Gladding ST (2014) Family therapy: History, theory, and practice. $6^{\text {th }}$ (Edn.), Pearson Higher.

9. Rice FP (1997) Intimate relationships, marriage and family. London.

10. Maghsoudi M, Mohammadi Sh (2010) Job burnout and marital distress. Woman in Development and Politics (Women's Research) 3(8): 57-71 


\section{Ergonomics International Journal}

11. Ebrahimi A, Najafi M, Mehrabi A, Sadeghi Z (2007) Relationship between Marital Conflict and Some Demographic Factors with the Chance of Migraine Headaches. Journal of Isfahan School of Public Health 89: 26.

12. Safari S, Goodarzi H (2011) Investigating the relationship between personality traits and burnout among faculty members and staff members of Azad University. Quarterly Journal of Leadership and Educational Management at Garmsar Azad University 3(3): 85-101.
13. Mousavi A, Navabinejad S, AtefVahid M (2005) The Effect of Premarital Relations on Marital Conflict. Journal of Counseling research 22: 6.

14. Mahoney KR (2006) The relationship of partner support \& coping strategies to marital adjustment among women with diabetes \& their male partner. Unpublished Doctoral dissertation, New York University.

15. Shafieenya A (1983) The Effect of Teaching Skills on Marital Conflict Resolution Skills Training on Improving Couple Interaction. Thesis for Master of Consultation, Allameh Tabatabaei University. 